Ideologia de gênero e seus sentidos: embates hegemônicos acerca do ensino e discussão de gênero na educação

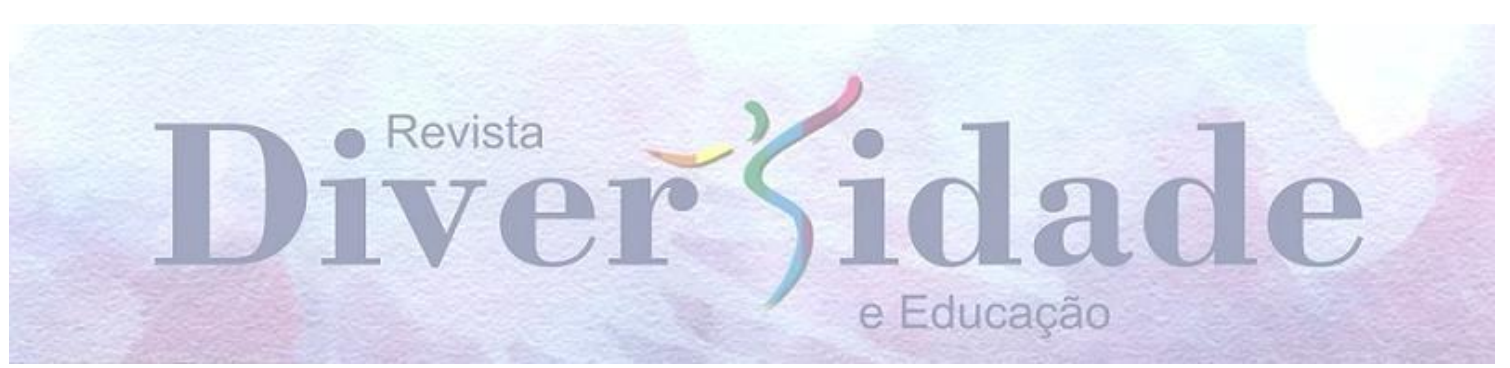

\title{
IDEOLOGIA DE GÊNERO E SEUS SENTIDOS: EMBATES HEGEMÔNICOS ACERCA DO ENSINO E DISCUSSÃO DE GÊNERO NA EDUCAÇÃO
}

\author{
IDEOLOGÍA DE GÉNERO Y SUS SIGNIFICADOS: LUCHA HEGEMÓNICA SOBRE \\ LA ENSEÑANZA Y LA DISCUSIÓN DE GÉNERO EN LA EDUCACIÓN
}

\section{GENDER IDEOLOGY AND ITS SENSES: HEGEMONIC FIGHTING ABOUT TEACHING AND GENDER DISCUSSION IN EDUCATION}

\author{
Silas Veloso de Paula Silva1
}

\section{RESUMO}

Este trabalho teórico-político discute a "ideologia de gênero" como um elemento discursivo de articulação transnacional. Nele, pretende-se abordar origem e constituição da mesma enquanto instrumento retórico que, desde 2014, tem causado um "pânico moral" nos segmentos sociais/políticos brasileiros. Ademais, procura-se apresentar outro sentido acerca do termo, em forma de conceito sociológico, ao mesmo tempo em que reitera uma perspectiva crítica. A partir da Teoria do Discurso, de Ernesto Laclau e Chantal Mouffe, pretende-se reflexionar a respeito dos significados e sentidos do referido elemento como uma ferramenta que põe em xeque o caráter democrático da educação, principalmente no que tange às ciências humanas. A metodologia de pesquisa utilizada é qualitativa, de caráter exploratório e aponta para a "ideologia de gênero" difundida em um momento agnotológico, na qual são institucionalizadas práticas de perseguição, censura e demonização dos sujeitos e grupos que trabalham com as teorias de gênero.

PALAVRAS-CHAVE: Educação. “Ideologia de gênero”. Política. Sociologia.

\section{RESUMEN}

Este trabajo teórico-político analiza la "ideología de género" como un elemento discursivo de una articulación transnacional. Está destinado a abordar su origen y constitución como un instrumento retórico que, desde 2014, ha estado produciendo un "pánico moral" en los segmentos sociales/políticos brasileños. Además, esta investigación busca aportar otro significado sobre el término, en forma de un concepto sociológico, al tiempo que reitera una

${ }_{1}$ Cientista Social pela Universidade Federal de Pernambuco. Mestrando do Programa de Pós-Graduação em Educação (UFPE/PPGEDU). Bolsista pela concessão de bolsas de Pós-graduação pela Fundação de Amparo à 
Ciência e Tecnologia do Estado de Pernambuco (FACEPE). 
perspectiva crítica. Con base en la teoría del discurso de Ernesto Laclau y Chantal Mouffe, buscamos reflexionar sobre los significados de dicho elemento, como una herramienta que cuestiona el carácter democrático de la educación, especialmente con respecto a las humanidades. La metodología de investigación que resultó en este trabajo es cualitativa, exploratoria y apunta a la "ideología de género" difundida en un momento agnotológico; donde están institucionalizados: prácticas de persecución, censura y demonización para sujetos y grupos que usan teorías de género.

PALABRAS-CLAVE: Educación. "Ideología de género". Política. Sociología.

\section{ABSTRACT}

This theoretical-political work discusses "gender ideology" as a discursive element of transnational articulation. It is intended to address its origin and constitution as a rhetorical instrument that, since 2014, has been producing a "moral panic" in the Brazilian social/political segments. Furthermore, this research seeks to bring another meaning about the term, in the form of a sociological concept, while reiterating a critical perspective. Based on the Discourse Theory of Ernesto Laclau and Chantal Mouffe, we seek to reflect on the meanings and meanings of such an element, as a tool that calls into question the democratic character of education, especially with regard to the humanities. The research methodology that resulted in this work is qualitative, exploratory and points to the "gender ideology" spread in an agnotological moment; where they are institutionalized: persecution, censorship and demonization practices for subjects and groups that use gender theories.

KEYWORDS: Education. "Gender ideology". Politics. Sociology.

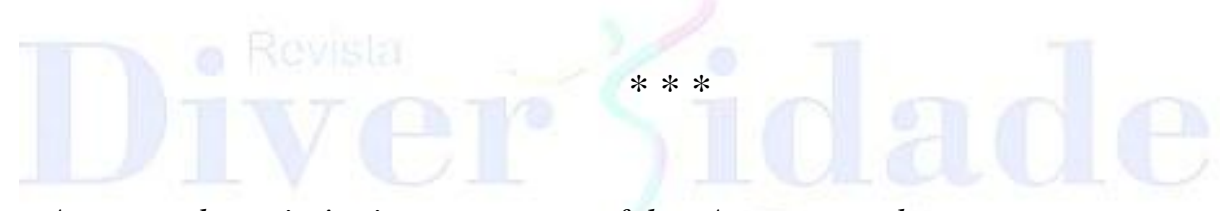

As rosas da resistência nascem no asfalto. A gente recebe rosas, mas vamos estar com o punho cerrado falando de nossa existência contra os mandos e desmandos que afetam nossas vidas. Marielle Franco

\section{Introdução}

“Atenção, atenção! Menino veste azul e menina veste rosa". A frase proferida, em 2019, por Damares Alves2 - atual ministra da Mulher, Família, e Direitos Humanos, do Governo Jair Bolsonaro - representa o estopim de um processo emergente no País com a elaboração do Plano Nacional de Educação (2014-2024). A partir de então, intensificou-se o debate acerca da expressão "Ideologia de Gênero"3, a qual, segundo Isabela Kalil e Sonia Correa (2020), configura-se como um discurso antigênero, e, como bem aponta Correa

\footnotetext{
2 Disponível em: <https://oglobo.globo.com/sociedade/menino-veste-azul-menina-veste-rosa-diz-damares-alvesem-video-23343024>. Acesso em: 15 de jun. de 2020.

3"Ideologia de Gênero" sempre aparecerá com aspas, quando fizer referência ao seu sentido político anti-gênero e ultraconservador, que ataca as TG, movimentos feministas e LGBTQI+. Adiante será elucidada a distinção entre essa lógica política de "ideologia de gênero" (com aspas) da abordagem sociológica (sem aspas).
} 
(2017), visa imobilizar políticas sexuais, teorias de gênero (TG) e o próprio movimento feminista e LGBTQI+4.

A busca por soluções em relação à erradicação das desigualdades de gênero e da discriminação com a população LGBTQI+ não é recente no Brasil. Atualmente, discussões sobre gênero, entrelaçadas às questões de diversidade sexual, podem ser compreendidas a partir do que Anna Oliveira e Gustavo Oliveira (2018) chamam de "embates hegemônicos". Tais conflitos são históricos no cenário político-educacional nacional e têm se intensificado, chegando inclusive às salas de aula. O mais polêmico dentre eles assume a face da "ideologia de gênero" - elemento discursivo de articulação transnacional, difundido estrategicamente como "instrumento retórico" a fim de combater o ensino e discussão de gênero e sexualidade nas instituições de educação.

A "ideologia de gênero" como elemento discursivo articulado transnacionalmente se explica a partir de dois alinhamentos teóricos-metodológicos. O primeiro provém da Teoria do Discurso (TD) em Ernesto Laclau e Chantal Mouffe (2015), na qual os discursos se constituem a partir de articulações emergentes de formações discursivas já existentes. No contexto de uma formação discursiva, os autores pontuam que articulação seria "qualquer prática que estabeleça uma relação entre elementos, de tal modo que a sua identidade seja modificada como um resultado da prática articulatória”; o discurso, por sua vez, seria a "totalidade estruturada resultante dessa prática articulatória" e os elementos, como caracterizamos a "ideologia de gênero", seriam "toda diferença não discursivamente articulada”. (LACLAU, E MOUFFE, 2015, p.178).

A partir dessas ferramentas teórico-metodológicas, concebe-se a "ideologia de gênero" como um elemento discursivo que se articula a outros elementos e, por meio desse processo, busca pela hegemonia de determinados discursos e fixação de lógicas sociaiss específicas, provenientes dos momentos de ascensão e avanço do conservadorismo e políticas de direita, não só no Brasil.

Tais lógicas sociais - representadas pelo bolsonarismo6, no Brasil - buscam a adequação da educação aos valores e demandas hegemônicas e políticas neoultraliberais. Isso se evidencia com a segunda abordagem que conduziu a presente inclinação sobre a problemática da “ideologia de gênero". Segundo Gabriela Ramirez (2020), este elemento antigênero representaria um movimento de base neointegralista católico que aliado a uma

4 Lésbicas, Gays, Bissexuais, Transexuais, Queer, Intersexo, entre outros.

${ }_{5}$ No sentido de Glynos e Howarth (2018).

6Disponível em: https://cartacampinas.com.br/2020/05/professor-descobre-origem-do-bolsonarismo-e-diz-queconsequencia-sera-catastrofica-ao-brasil/. Acesso em: 17 de jun. de 2020. 
aliança político-cultural com o fundamentalismo neopentecostal, funciona ao modo político neoliberal.

Nesse sentido, compreende-se a multiplicidade de sujeitos e elementos discursivos que se articulam em prol de uma (re)configuração social. A partir da abordagem das lógicas de Glynos e Howarth (2018), busca-se verificar quais elementos discursivos associam-se à "ideologia de gênero" e como tentam constituir um discurso hegemônico a partir de suas lógicas sociais.

Hodiernamente, vivencia-se um período de ataques à laicidade do Estado e à diversidade, no qual a própria produção/construção dos conhecimentos e saberes científicos tem sido subjugada em favor de um falseamento do social e de medidas agnotológicas 7 (de produção e investimento da ignorância). Essas (re)configurações do social justificam pesquisas voltadas a compreender, não apenas quais os impactos dos discursos disputadores das demandas educativas em torno de questões relacionadas ao gênero e à sexualidade, mas como tais emergem e o que torna (im)possível suas articulações e hegemonias.

Dessa forma, move-se esforços para, através de uma abordagem teórico-metodológica pós-estruturalista - mais especificamente, a TD de Laclau e Mouffe (2015) — refletir acerca dessas problemáticas tão imbricadas no momento histórico vigente, tendo como premissa a concepção do social como ontologicamente político. A respeito dos posicionamentos e de toda argumentação presentes nesta produção, adota-se o posicionamento descrito por Lorenzo Bernini (2018):

\footnotetext{
Por também estar pessoalmente envolvido nessas discussões e fraturas, não posso assumir, aqui, um ponto de vista neutro e desinteressado, como se descrevesse cientificamente um fenômeno sociológico que não me diz respeito. Pelo contrário, sou um sujeito partícipe, interessado, que assume um posicionamento claro em contraposição aos movimentos "anti-gender" e, ao mesmo tempo, defende uma visão específica no interior do campo de resistência feminista e LGBTQI+ (BERNINI, 2018, p. 543).
}

Nesse sentido, ao mesmo tempo em que se posiciona em relação à defesa do ensino sobre TG e diversidade sexual, faz-se uma critica às lógicas sociais cis-heteronormativas e patriarcais, as quais reduzem problemas e fenômenos sociais à crenças e valores de grupos seculares por meio de discursos biologizantes. Contudo, é preciso apontar o alinhamento do posicionamento adotado a outros discursos científicos já existentes, contrários às lógicas

7 No sentido de Robert N. Proctor e Londa Schiebinger (2008) na obra: Agnotology The Making and Unmaking of Ignorance. 
sociais reacionárias, como os Estudos feministas e/ou de gênero, a teoria Queer, os estudos culturais e decoloniais e os próprios saberes que afloram no seio dos movimentos sociais os quais se constituem na pluralidade e diversidade, evidenciando posição oposta à crença da existência de uma "Ideologia de Gênero".

É relevante que estes embates, significados e sentidos sejam abordados no campo da intelectualidade e da ciência, não de forma polarizada, mas levando em consideração as suas relações interdiscursivas, sendo o conhecimento científico, como bem aponta Oliveira (2018), também um discurso que não está externo ao campo da discursividade nem à concepção do social como ontologicamente político:

\footnotetext{
Mais que isso, a perspectiva pós-estruturalista insiste - e esse é um ponto que a diferencia das abordagens construcionistas clássicas - em levar às últimas consequências o reconhecimento de que o sujeito e o trabalho de pesquisa não existem em um plano ontologicamente e/ou epistemologicamente separado da realidade pesquisada.(OLIVEIRA, G., 2018, p. 185).
}

Abordando a produção científica como objeto inserido em uma formação discursiva, a composição argumentativa deste trabalho considera apropriado à construção do problema científico produzir discursos de oposição à agnotologia - que vem sendo operacionalizada sobre o social - e à própria descaracterização direcionada às ciências humanas pelo governo8 vigente9, reiterando a ampliação de espaços de diálogo nos campos educacionais, sendo estes campos discursivos de resposta e resistência às barreiras impostas à diversidade e a pluralidade em prol de uma sociedade que preze pela justiça social e equidade e vise à erradicação das desigualdades, bem como as de gênero e as não inseridas nas lógicas sociais cis-heteronormativas.

\section{Articulando as abordagens teóricas sobre os sentidos em ideologia de gênero}

Seguindo na contextualização da "Ideologia de Gênero", Miskolci e Campana (2017) sugerem que nos últimos anos, em diversos contextos nacionais - sobretudo na Europa e posteriormente na América Latina - , emergiram debates sobre o que seria denominado, no Brasil, de "ideologia de gênero" por grupos religiosos e laicos, conhecida em países como

8 Em abril de 2019, por exemplo, o atual presidente do Brasil e ex-militar Jair Bolsonaro, defendeu em seu twitter a descentralização dos investimentos para os cursos de sociologia e filosofia no país.

9Disponível em: <https://g1.globo.com/educacao/noticia/2019/04/26/bolsonaro-diz-que-mec-estudadescentralizar-investimento-em-cursos-de-filosofia-e-sociologia.ghtml>. Acesso em: 09 de jun. de 2020. 
França e Itália, conforme Miguel (2016), como "teoria do gender” ("théorie du gender", “teoria del gender"). Tal expressão, em termos da TD, representa um elemento discursivo que se manifestou em dado momentolo a partir da reação de setores tradicionais da Igreja Católica, articulada às posições de grupos políticos majoritariamente de direita, aos avanços de pautas acerca dos direitos sexuais e reprodutivos, a qual tem sido difundida, principalmente, por grupos evangélicos conservadores. Contudo, como bem aponta Prado e Correa:

\begin{abstract}
No caso brasileiro, é flagrante, por um lado, o perfil católicoevangélico da ofensiva, mesmo quando a forte frequência do Vaticano, como mentor intelectual dessa cadeia discursiva, seja obscurecida pela estridência evangélica. Por outro lado, também é fundamental, reconhecer a contribuição da participação de outras vozes religiosas como kardecistas e judeus de direita e de setores seculares, como os ditos liberais do Movimento Brasil Livre (MBL), juristas, médicos/as, professoras/es e políticos que não são necessariamente religiosos do qual um exemplo é o Escola sem Partido(PRADO, CORREA, 2018, p. 445).
\end{abstract}

As articulações que constituem a "ideologia de gênero" não se mobilizam de forma homogênea, tampouco seguem estrutura fixa. Esse fato se mostra mais evidente quando são analisados seus surgimentos e difusão em cada país. No entanto, sugere-se como ponto nodal ou pauta incomum dessas articulações a contraofensiva e/ou o combate ao avanço em matérias de direitos sexuais e reprodutivos.

Sob ótica feminista, conforme Maria Betânia Ávila (2003, p. 466), compreende-se os direitos reprodutivos como "o respeito à igualdade e à liberdade na esfera da vida reprodutiva" e os direitos sexuais como "a igualdade e a liberdade ao exercício da sexualidade", implicando-se a concepção de tais como dimensões da cidadania e consequentemente da vida democrática. "Tratá-los como dois campos separados é uma questão crucial no sentido de assegurar a autonomia dessas duas esferas da vida, o que permite relacioná-los entre si e com várias outras dimensões da vida social.” (ÁVILA, 2003, p. 466).

A posição de negar a importância dos direitos reprodutivos e sexuais levou grupos conservadores a escolherem como inimigos o feminismo e as TD, associadas posteriormente

10Segundo Laclau e Mouffe (2015, p. 178), momentos fazem parte de uma prática articulatória e seria: "as posições diferenciais, na medida em que apareçam articuladas no interior de um discurso". 
ao combate de um suposto marxismo cultural.11 No entanto, não é recomendável generalizar as identidades de sujeitos e grupos protagonistas nos ataques antigênero ou atribuir a difusão de tal instrumento retórico a grupos religiosos tradicionais e políticos de direita, como bem fundamentam Prado e Correa (2018):

Há movimentações que se articulam com outros grupos e organizações
reacionárias e ultraconservadoras como partidos de extrema direita,
colégio de pediatras antidireitos LGBTI, grupos de psiquiatras e
psicólogos/as que defendem as chamadas terapias de reversão da
homossexualidade e a manutenção de categorias patologizantes para
nomear a experiência de pessoas trans e intersexuais, ginecologistas
que são contra o aborto, pedagogos que repudiam a educação sexual,
juristas e operadores de justiça que preconizam concepções ortodoxas
do direito, mas também vozes de esquerda, psicanalistas e psicólogas,
como também grupos feministas marcam a heterogeneidade das
articulações desta ofensiva (PRADO; CORREA; 2018, p. 444, grifo
do autor).

Dada a heterogeneidade dos grupos que compõem tal articulação e difundem a “ideologia de gênero", será utilizada neste trabalho a expressão "grupos antigênero" de quando for preciso fazer referência às identidades e sujeitos difusores da "ideologia de gênero" em seu sentido ultraconservador e de ataque reacionário às TD.

No tocante ao campo da educação, os grupos antigênero apontam a abordagem de temáticas sobre gênero e diversidade sexual, nas escolas, como manipulação, inversão de valores e incentivo à homossexualidade. Utilizando-se do ideal de família nuclear e tradicional e da exaltação a uma suposta natureza sexual, caracterizam as discussões de gênero e sexualidade na educação como conteúdos provenientes do processo de doutrinação dos governos de esquerda que, supostamente, adentra no espaço escolar por meio de professores/as militantes.

Milskolci e Campana (2017, p.725), apresentam a "ideologia de gênero" como instrumento fomentador de determinado "empreendedorismo moral" a respeito da legitimidade do ensino e discussão de gênero nos espaços educacionais. - Essas narrativas são bem mais bem compreendidas quando analisadas de forma transnacional, como tem feito o Observatório de Sexualidade e Política (SPW-Sexuality Policy Watch), que, desde 2017, mapeia e direciona as análises sobre "ideologia de gênero" na América Latina12. Ainda segundo Miskolci e Campana (2017) existem fatores paralelos ao avanço da "ideologia de

11 Um movimento ideológico, cujo objetivo seria converter, a partir de valores culturais, a sociedade em um modelo comunista e de governos de esquerda.

12 Para mais informações, ver: RAMÍREZ, Arguedas Gabriela. "Ideología de género", lo "post-secular”, el fundamentalismo neopentecostal y el neointegrismo católico: la vocación anti-democrática. 2020. Observatorio de Sexualidad y Política (SPW). 
gênero" em países como o Brasil, Argentina e Chile, por exemplo. Entre esses fatores está a apreensão, por parte de políticos de direita e setores religiosos, em relação à chegada de mulheres na presidência13, assim como o avanço e ascensão de governos e políticas de esquerda. Estes representariam, portanto, possíveis progressos em questões referentes aos direitos sexuais e reprodutivos, algo interpretado como ameaça para os grupos mais conservadores.

O argentino Jorge Scala (2011), abertamente ultraconservador, ilustra as referidas apreensões em sua obra "Ideologia de Gênero - o neototalitarismo e a morte da família." Scala advoga a equiparação das TG a um modelo de totalitarismo semelhante ao comunismo14 e ao nazismo15. Para o advogado, a "ideologia de gênero" seria um instrumento políticodiscursivo de alienações globais a fim de estabelecer uma forma sutil de impor — por meio da linguagem - uma separação entre sexo biológico e gênero, sendo este, na defesa de Scala, uma ideia de "sexo construído socialmente". Scala, por meio de sua concepção de gênero, se apresenta como defensor da "ideologia de gênero" em seu sentido reacionário. Nesse sentido, nota-se que o autor realiza uma autointerpretação das TG a partir de lógicas fantasmáticas.

A abordagem das lógicas se trata de um modelo crítico-explicativo e teóricometodológico criado por Glynos e Howarth (2018) para ampliar as im(possibilidades) metodológicas, dialogando com a TD, de Laclau e Mouffe. Glynos e Howarth (2018, p.54-56) chamam de lógicas sociais "o que é um regime ou prática social particular" e de lógicas fantasmáticas aquilo que é resistente à mudança das práticas sociais ou práticas políticas, “a inércia das práticas sociais".

Seja no contexto das práticas sociais ou das práticas políticas, a fantasia opera de modo a ocultar ou "bloquear" a contingência radical das relações sociais. Isso é feito através de uma lógica ou narrativa fantasmática que promete uma plenitude-do-porvir, uma vez que um obstáculo implícito ou numerado é superado - a dimensão beatífica da fantasia-, ou que prevê o desastre se o obstáculo se revela insuperável, que pode ser denominado a dimensão terrífica da fantasia. (GLYNOS; HOWARTH, 2018, p.56).

Além do sentido reacionário e fantasmático, pretende-se apresentar outro sentido sobre ideologia de gênero, a sua face enquanto discurso sociológico. Annie Kroska, (2007, p. 1867) em The Blackweel Encyclopedia of Sociology, traz grande contribuição a respeito dessa outra

14 Visão do autor acerca do que seria comunismo.

15 No Brasil é muito comum a utilização da palavra "feminazi" por grupos de direita, para rotular feministas de forma pejorativa. 
faceta. Segundo a autora, "tanto a ideologia de gênero quanto a ideologia de papéis de gênero referem-se a atitudes em relação aos papéis, direitos e responsabilidades das mulheres e homens na sociedade". Butler, (2019), em seu texto "Precisamos parar o ataque à" “ideologia de gênero", dialoga de certa forma com a abordagem sociológica tratada por Kroska, no sentido de que a "ideologia de gênero", a partir da lógica dos grupos antigênero, emerge como mais uma forma de conceber as TG e sexualidade. Concepção esta, conforme as discussões desenvolvidas até aqui, fundamentada em fantasias sociais. Uma dessas fantasias, por exemplo, afirma que Judith Butler, filósofa atuante nos debates de gênero e sexualidade, seria a grande difusora ou "mãe" da "Ideologia de Gênero".

No que diz respeito ao campo educacional, o texto de Butler é pertinente a esta análise em especial quando se utiliza do termo "pedagogia em diversidade de gênero". Esta expressão pode se referir às formas de significação acerca do gênero e da sexualidade no ambiente escolar. Sob a perspectiva antigênero, seria uma pedagogia fantasiosa, caracterizando-se como "um exercício dogmático que prescreve como os estudantes deveriam pensar ou viver” (BUTLER, 2019). Posto isto, uma pedagogia em diversidade de gênero pode tanto tomar posições em relação à defesa do ensino e discussão de gênero, como negar a relevância e os benefícios de tais discussões no ambiente escolar.

Tais pedagogias se evidenciam a partir de Bernini (2018, p. 548) ao destacar uma fala de Jorge Mario Bergoglio, o então Papa Francisco, em Abril de 2013, advertindo seus/suas fieis a respeito "dos horrores da educação manipuladora", a qual poderia transformar as escolas em "campos de reeducação" comparáveis aos das "ditaduras genocidas do século XX". Tais enunciados são provocativos e convidativos a pensar sobre os sentidos de pedagogias em diversidade de gênero que estão em disputa.

Partindo de uma abordagem sociológica, o conceito de Ideologia de Gênero (sem aspas) reflete as relações estabelecidas pela execução dos papéis de gênero, seja de forma ampla ou dentro de um campo de dominação específico, por exemplo, o econômico, familiar, jurídico, e/ou de dominação social (KROSKA, 2007). Segundo Silva; Nara e Barreto (no prelo), tais campos possuem construções unidimensionais que variam de tradicional, conservadora ou antifeminista para igualitária, liberal ou feminista. De acordo com essa perspectiva, ideologias tradicionais de gênero ou — a partir do texto de Butler — pedagogias tradicionais de gênero têm ligação direta com a estrutura familiar patriarcal, na qual homens e mulheres desenvolvem atividades a partir de papéis sociais distintos, sendo a mulher subjugada nessa relação de poder e diferença. Ainda segundo Silva; Nara e Barreto (No prelo), tais associações são feitas através da negação do conceito de gênero e das 
configurações atribuídas aos papéis sociais de acordo com sexo biológico. Ademais, há outro sentido sobre o conceito da ideologia de gênero que tem sido aplicado aos estudos feministas e de gênero conforme Kroska (2007): a existência de crenças sociais generalizadas que legitima as desigualdades existentes entre os papéis de gênero. Nessa abordagem, a autora elucida a ideologia de gênero já no seu sentido antigênero:

\begin{abstract}
Por exemplo, Lorber (1994: 30) define ideologia de gênero como "a justificativa de status de gênero, particularmente, sua avaliação diferencial. A ideologia dominante tende a suprimir as críticas fazendo com que essas avaliações pareçam naturais." Usada dessa maneira, a ideologia de gênero não é uma variável que varia de conservadora a liberal; em vez disso, refere-se a tipos específicos de crenças - aqueles que apoiam a estratificação de gênero" (LORBER, 1994 apud KROSKA 2007, p.1867).
\end{abstract}

A partir de análises como esta, viabiliza-se a abordagem da "ideologia de gênero" (antigênero) como um tipo específico de crença/fantasia que apoia a estratificação de gênero. Mais que isso, pode-se apontar para os perigos de tal instrumento retórico polissêmico em relação à intensificação e ampliação da naturalização de violências, discriminação e exclusão de sujeitos e identidades nos espaços políticos/educacionais.

De acordo com Louro (2000a), a escola é um ambiente que exerce uma "pedagogia da sexualidade". Isso envolve o uso de linguagens, estratégias e táticas institucionais que legitimam determinadas práticas e identidades sexuais, em detrimento da marginalização de outras. Contudo, a autora pontua que, inevitavelmente, os discursos sobre sexualidade continuam se modificando e se multiplicando e, com isso, crescem novas formas de resistência de modo apelativo, provenientes dos grupos mais conservadores, os quais buscam a recuperação ou manutenção dos valores e práticas tradicionais. Diante disso, pretende-se abordar de forma explicativa e crítica o discurso sobre "ideologia de gênero", caracterizando tal elemento discursivo como operacionalizado por uma lógica fantasmática de gênero: uma crença que apoia a estratificação de gênero — com pretensões antigênero —, legitimadora de desigualdades de gênero e orientação sexual nas instituições de educação e espaços políticos/sociais, atacando de forma direta as TG e os avanços de pautas políticas dos movimentos feministas e LGBTQI+.

Após essa seção de contextualização, este trabalho segue dividido em duas partes, cada uma com seus respectivos objetivos a seguir: 1- Situar a "ideologia de gênero", no seu sentido ultraconservador e reacionário, como elemento de articulação discursiva transnacional, que, inserido em um momento de demandas antipolíticas, trata o conhecimento 
científico a partir de posições agnotológicas; 2- Reiterar as instituições de educação como espaços discursivos privilegiados no que tange as discussões e debates sobre gênero e sexualidade, situando a "ideologia de gênero" como uma crença que apoia a estratificação do gênero e quando analisada em sua articulação política, e conceituada sociologicamente, revela os "embates hegemônicos" em torno da educação, assim como da vida e da visibilidade de identidades e sujeitos.

\section{"Ideologia de gênero" como crença/elemento de uma articulação discursiva: posições agnotológicas de conhecimento e os ataques às teorias de gênero (TG)}

Baseando-se em Oliveira (2018, p. 210), constatou-se que as lógicas fantasmáticas, muitas vezes, re(produzem) seus significados de modo difuso. Tal difusão de sentidos também se aplica à “ideologia de gênero", tanto entre os sujeitos em sociedade como entre as próprias pesquisas acadêmicas ao tentarem definir ou caracterizar tal expressão.

Para elucidar a difusão entre os sujeitos em sociedade, Silva (2019, no prelo) afirma — em sua pesquisa acerca das narrativas de professores/as sobre "ideologia de gênero" na cidade do Recife-PE - que alguns/as dos/as docentes entrevistados/as se referiam à "ideologia de gênero" como uma expressão que significava “a importância do ensino e discussão de gênero no ambiente escolar". O segundo exemplo de difusão — nas pesquisas acadêmicas - pode ser constatado a partir de simples pesquisa bibliográfica, na qual o termo aparece como: "falácia” (Reis e Eggert, 2007); “termo antigênero" (Ramirez, 2020); “cruzada católica" (Bernini,2018); ou "campo discursivo de ação" (Miskolci e Campana, 2017). Contudo, no caso das pesquisas acadêmicas, tal multiplicidade de caracterização pode ser analisada como uma polissemia. A difícil tarefa posta a esta pesquisa e a outras futuras seria explicar ou identificar o ponto nodal ou a noção equivalente a todos esses termos, aparentemente diferentes.

Apesar da complexidade dessa questão polissêmica, é possível analisar os impactos que estes diversos sentidos produzem sobre as relações sociais. Em outras palavras, é possível compreender e reconstruir os significados carregados pelos referidos sentidos, seja como crença/fantasia que apoia a estratificação de gênero — antigênero — ou como conceito sociológico - ideologias de papeis de gênero que variam em seus sentidos.

Nesse sentido, seja no campo simbólico ou semiótico, a "ideologia de gênero" pode ser considerada como um jogo de palavras, um instrumento retórico que se explica a partir do termo “significante flutuante”. Segundo Bernini (2018, p. 549), o significado do termo 
"gênero" sempre esteve em disputa e, como já foi discutido a partir de Kroska (2007), uma crença que apoia desigualdades de gênero tem a sua própria concepção de gênero: uma criação pecaminosa que destrói a natureza sexual determinada por "Deus".

Quando um significante desliza entre diferentes processos de significação, sendo identificado de maneiras distintas, catalisando sentidos de grupos específicos do conjunto da heterogeneidade social, mas simultaneamente não assumindo a condição de representante do todo, ele passa a ser concebido como um significante flutuante, sendo vinculado a diversos sentidos específicos (COSTA; PEREIRA, 2013, p. 159).

Bernini (2018) sugere que o termo gênero, já em disputa, foi unido de forma estratégica ao termo ideologia, transformando-se, dessa forma, em uma ferramenta retórica. Acrescenta-se à análise do autor a dimensão fantasmática na construção desse dispositivo, o qual se desenvolve na caracterização de uma TG inimiga, capaz de destruir a família tradicional e a natureza sexual de homens e mulheres em sociedade. Tal fantasia é por si só uma forma - ideologia - de conceber o gênero e a sexualidade. Antagonistas a este tipo de ideologia ou lógica de gênero, estariam os discursos feministas, LGBTQI+, as TG e os discursos que ecoam em defesa dos direitos sexuais e reprodutivos.

Para os grupos antigênero, todas as teorias, estudos, pessoas, formas de educação e organizações políticas que se utilizam da categoria gênero para explicar/criticar/refletir as relações e os papeis de homens e mulheres em sociedade são difusores da suposta "ideologia de gênero". O que tais grupos esquecem ou desconhecem é que, consoante a uma abordagem sociológica, essa investida linguística os configura como empreendedores de uma ideologia de gênero, reacionária e conservadora, em forma de crença e fantasias.

É pertinente às ciências humanas desmistificar os sentidos difusos do que se conhece por "ideologia de gênero", pois a própria sociologia permite a análise da mesma enquanto uma crença reacionária. Nesse sentido, o presente trabalho entra em consonância com Butler, quando a mesma afirma que "precisa-se parar o ataque à 'ideologia de gênero'”. Mais que isso, é possível mostrar que a confusão de seu significado é algo estrategicamente político, um “jogo de palavras”, seja em torno da gramática ou de sua força discursiva sobre o social. Além disso, nota-se, a partir da genealogia do termo - inicialmente tratado como "teoria do gênero" ou "abordagens do gênero" —, a possibilidade de se chegar à compreensão de sua dimensão fantasmática, seja em análises de campo discursivo transnacional ou no espaço discursivo da política/educação no Brasil. 
A abordagem das lógicas de Glynos e Howarth (2018) permitem a compreensão dessa difusão ou diferenciação. A “ideologia de gênero", em seu sentido ultraconservador e antigênero, representa e está a serviço de uma lógica social que anula a importância da diversidade sexual e das questões de gênero, partindo de regimes morais/políticos/religiosos sobre o sexo e os papeis de gênero. Tal lógica social sugere que as diferenças entre homens e mulheres são meramente "sexuais" e devem ser pensadas a partir de uma ótica biologizante, a qual, de acordo com Paternortee e Kuhar (2018, p. 508), concebe as TG como "matriz ideológica que inspira um conjunto de reformas éticas e sociais 'abomináveis"”.

Ignorando completamente a história do conceito de gênero, autores/as do campo antigênero tem como ponto de partida os experimentos problemáticos de John Money nos anos 1950 e, de forma equivocada, consideram Judith Butler como a mãe da "ideologia de gênero". Curiosamente, eles/as colocam num mesmo saco os pensamentos de Simone de Beauvoir, Shulamith Firestone, Monique Wittig, Germain Greer, Margaret Sanger, Alfred Kinsey, Wilhelm Reich e, às vezes, até elaborações de Herbert Marcuse, Sigmund Freud e Friedrich Engels. Em poucas palavras, a expressão "ideologia de gênero" busca oferecer um enquadre interpretativo para explicar a adoção dessas reformas e, ao mesmo tempo, conectar atores e atrizes muito díspares numa suposta aliança conspiratória do "gênero" (Trillo-Figueroa, 2009; Montfort, 2011; Scala, 2011; Peeters, 2013). (PATERNOTTE; KUHAR, 2018, p. 508).

Já a ideologia de gênero - em seu sentido feminista/crítico — opera como uma lógica política, na qual, através de recursos conceituais, analíticos e históricos, se faz uma crítica ao elemento discursivo "ideologia de gênero" (antigênero) fundamentado na lógica fantasmática. Esta, por sua vez, afirma a existência de um exército de doutrinadores/as do gênero, proveniente dos governos de esquerda, que tem como objetivo destruir o gozol6 e a estabilidade da família tradicional/universal por meio da atuação de professores/as militantes.

Além de contrariar a concepção antigênero, a perspectiva crítica e feminista compreende a existência de ideologias de gênero, isto é, formas distintas de abordar o gênero e reconhece: 1- a categoria "gênero" e a própria ideologia de gênero como significante flutuante ou conceito polissêmico; 2- o valor da reconstrução genealógica do termo ideologia de gênero; e, consequentemente, 3- a compreensão da ideologia de gênero como ferramenta utilizada para refletir, explicar e criticar as relações e os papeis de homens e mulheres na sociedade, inclusive para além das estruturas binárias.

${ }_{16}$ Segundo Oliveira, G. (2018), o conceito de lógicas fantasmáticas é “desenvolvido particularmente por Glynos e Howarht (2007) - a partir do modelo lacaniano de fantasia - para buscar aprofundar a reflexão sobre o que Laclau (2013, p. 160) identifica como a força que mobiliza e torna possíveis as operações significantes, que está relacionada à dimensão do afeto ou do (gozo)". (OLIVEIRA, G., 2018, p. 198). 
No que diz respeito à "ideologia de gênero" como elemento discursivo, tal concepção possui relação direta com o conceito de hegemonia, em Laclau e Mouffe (2015). Localizá-la em uma estrutura discursiva é se perguntar, sobretudo, sobre o seu papel no processo de hegemonização dos discursos. Dentro desse cenário, o seu sentido antigênero configura-se como elemento discursivo parte de um momento articulatório transnacional - principalmente por meio dos horizontes apontados por Silva; Nara e Barreto; (no prelo) sobre a política sexual do neoliberalismo — ou em termos de abordagem das lógicas - lógica sexual/social do neoliberalismo.

No caso específico do Brasil, a "ideologia de gênero" não aparece de forma isolada. No campo da educação, por exemplo, ela surge interdiscursivamente junto a outros elementos discursivos e/ou "demandas educacionais", como as ideias de doutrinação nas escolas, marxismo cultural, kit-gay, privatização das universidades públicas e o movimento anticiência, ressaltado por Lopes (2019).

Para situar tais elementos historicamente, jamais de maneira exata, demarca-se o golpe de 2016 como porta de entrada para a emergência dessas articulações em prol de práticas discursivas que levaram o atual Presidente da República, Jair Messias Bolsonaro, ao poder. Lopes (2019, p. 02) argumenta que o movimento antipolítica, no Brasil, associado ao pensamento conservador e anti-intelectual, teve início com as ações políticas de grupos conservadores que se mobilizaram mais intensamente após as manifestações ocorridas em junho de 2013. "O Movimento Brasil Livre (MBL), por exemplo, foi oficialmente criado em 2014 e o Tradutores de Direita em 2013. Ambos tiveram seu ápice hegemônico com o golpe político-jurídico-midiático que levou ao impeachment de Dilma Rousseff” (LOPES, 2019, p. 02). Além disso, a autora pontua que:

\begin{abstract}
Alguns dos embates centrais durante a campanha eleitoral de 2018 se desenvolveram em torno da educação. O movimento Escola sem Partido, as críticas às políticas de gênero, à obra e à pessoa de Paulo Freire, e a proliferação de fake news referentes às políticas de gênero e sexualidade na educação e ao que se privilegia no currículo foram alguns dos momentos de uma articulação discursiva que levou Bolsonaro à presidência da República. Mesmo após a eleição, é em torno das políticas educacionais e dos embates com as universidades públicas que vem se dando grande parte dos movimentos políticos antagônicos constituintes do social. (LOPES, 2019, p. 04)
\end{abstract}

Apesar de compreender a não reivindicação da "ideologia de gênero" apenas por grupos de direita, é em consonância com as reflexões de Lopes (2019) que se atribui aqui o protagonismo de sua difusão no Brasil aos setores conservadores — religiosos ou não — sem 
correr o risco de generalizações diante do que já foi apresentado anteriormente sobre os grupos antigênero.

No campo educacional, tais grupos políticos/religiosos têm impactado diretamente na concepção do conhecimento cientifico, principalmente relacionado às ciências humanas. $\mathrm{O}$ que Lopes (2019) chama de anti-intelectualidade, presente na política brasileira atual, relaciona-se diretamente com o conceito de agnotologia, o qual contribui na compreensão das posições políticas/religiosas anticiência que buscam apagar a legitimidade histórica do conceito de gênero do espaço discursivo das ciências humanas.

O propósito da agnotologia seria "promover o estudo da ignorância", desenvolvendo ferramentas para compreender como e porque várias formas de conhecimento não 'emergiram', ou desapareceram, ou foram retardadas ou negligenciadas por longo tempo, para melhor ou para pior, em vários pontos da história (PROCTOR \& SCHIEBINGER, 2008, P. VII APUD LEITE, 2014, p. 179).

As posições agnotológicas por parte de discursos religiosos e políticos/institucionais não são novidade em cenários de instabilidade e conflito. Na verdade, são lógicas políticas estratégicas fixadoras de sentidos e significados acerca de lógicas sociais. No caso da "ideologia de gênero", a necessidade de hegemonizar a lógica social da família tradicional e das diferenças entre homens e mulheres, por meio do discurso biológico, fez-se eleger a categoria gênero como o grande inimigo de seus horizontes de "realidades".

Após situar a "ideologia de gênero" como elemento discursivo operante através da lógica fantasmática e integrante do processo de articulação discursiva emergente da ascensão dos governos de direita e da intensificação de seus embates e disputas contra lógicas sociais e posições de esquerda, voltar-se-á à discussão genealógica da "ideologia de gênero".

Miskolci e Campana (2016, p. 726) apontam que o termo "ideologia de gênero" começa a alardear seus perigos em países europeus a partir de 2008. Contudo, outros momentos foram cruciais para a emergência de tal elemento discursivo, como quando a escritora Dale O’Lery publicou a “Agenda de Gênero: redefinindo a Igualdade”, em 1997. No texto, a autora fez duras críticas ao movimento feminista, afirmando que o mesmo fomentava ideologias contrárias às diferenças biológicas entre homens e mulheres. Nessa mesma época, os textos do então cardeal da Igreja Católica, Joseph Alouisius Ratzinger, criticavam termo "gender", concebendo-o como conceito dissimulador dos limites do ser humano enquanto ser biológico. Segundo Bernini (2018): 
Tudo começou em 1995, durante o pontificado de Wojtyla, quando os/as convidados/as do Vaticano na Conferência Mundial sobre Mulheres em Pequim protestaram contra o uso do termo "gender" em relatórios e documentos da conferência. Iniciou-se, então, um debate dentro da Igreja, que resultou na publicação, em 2003, do Lexicon: termos ambíguos e discutíveis sobre família, vida e questões éticas, um grande volume de ética familiar organizado pelo Pontifício Conselho para a Família (Pontificio Consiglio per la Famiglia, 2003). Aqui, a expressão "ideologia do gênero" fez sua aparição oficial no verbete "Ideologia de gênero: seus perigos e alcances", de Oscar Alzamora Revoredo; enquanto Jutta Burggraf assinou o verbete "Gênero" (BERNINI, 2018, p. 548).

A preocupação com a posição e desempenho de papéis das mulheres na sociedade apresenta-se como carro-chefe dessas articulações e contraofensivas. Os discursos opostos às "concepções de gênero" reafirmavam e ainda reafirmam a complementariedade entre os sexos, afirmando a existência do gênero feminino, pautado o mesmo como detentor de “dons", dados por Deus, como o cuidado e a capacidade de atender as necessidades dos/as outros/as. Estas ideias sexistas, segundo Miguel (2016), eram centrais à elaboração dos pensadores católicos contrários às concepções de gênero ao mesmo tempo em que era reproduzido o papel de submissão da mulher como algo benéfico, exaltando-se o cumprimento destes papéis. Construía-se então uma contraofensiva, por parte da Igreja Católica, conferindo ao feminismo o status de rebaixador da mulher e suas especificidades divinas. Ainda segundo Miskolci e Campana (2017, p. 726), o texto “O Sal da Terra”, de Ratzinger (1997), “constituiu-se como peça-chave para o começo desta contraofensiva política-discursiva contra o feminismo e sua proposta de reconhecimento e avanço em matéria de direitos sexuais e reprodutivos." Nesse sentido, configurava-se um ataque às ideias feministas gestadas há décadas, e uma reação direta à "Conferência Mundial de Beijing" sobre a mulher, organizada em 1995 pelas Nações Unidas. Nela, propôs-se substituir o termo "mulher" por "gênero" em uma agenda internacional, estabelecendo que:

[...] todas as políticas e instituições econômicas [dos governos e da comunidade internacional], assim como aqueles encarregados de conceder recursos devem adotar uma perspectiva de gênero (DECLARAÇÃO E PLATAFORMA DE AÇÃO DE BEIJING, 1995 apud MISKOLCI e CAMPANA, 2017, p. 725).

A partir de então, não só a Igreja Católica, mas outros setores religiosos conservadores, passaram a combater a "perspectiva de gênero", afirmando ser uma ferramenta 
ideológica de dominação, conhecida e apresentada atualmente, de forma difusa, como "ideologia de gênero".

Miguel (2016) pontua que a preocupação de tais setores se centralizou na educação e, em certa medida, nos meios de comunicação de massa, por afirmarem que as crianças seriam o grupo mais vulnerável aos males de tal "ideologia", pois seriam "doutrinadas" a se desenvolverem "incorretamente" ou impedidas de consolidarem suas identidades masculinas ou femininas 'naturais'. De acordo com Miguel (2016), desde 2014, vários projetos de lei têm sido apresentados no Congresso Nacional com o objetivo de evitar uma suposta "doutrinação ideológica" nas instituições de ensino. Tais discursos conservadores, ainda para o autor, surgem no Brasil a partir de confluências entre o libertarianismo17, o fundamentalismo religioso (difundido entre evangélicos e setores mais conservadores da Igreja Católica) e o antigo anticomunismo, ressurgido através da comparação das políticas implementadas nos anos de governo do Partido dos Trabalhadores (PT) ao "bolivarianismo"18. Este veio a ser apresentado como "encarnação" do comunismo no Brasil, gerando sobreposições entre anticomunismo e antipetismo.

Os discursos que constituem e se relacionam com a "ideologia de gênero" buscam, por meio do estabelecimento do "pânico moral"19, descaracterizar as TG ao mesmo tempo em que reforçam o papel de submissão da mulher e naturalizam os papéis de opressão que as mesmas vivenciam, justificando-se em aspectos biológicos e em fundamentos religiosos de setores conservadores/reacionários/hegemônicos do cristianismo. Tais pânicos morais podem ser amplificados por meio de veículos de comunicação como a internet. Em 2018, no Brasil, a falsa notícia (Fake News) sobre o "kit gay" foi utilizada na campanha do atual presidente da república, Jair Bolsonaro, na época membro do (PSL)20, que acusou Fernando Haddad (PT), seu opositor, de distribuir um kit de incentivo ao "homossexualismo" com linguagens, figuras e conteúdos eróticos para crianças nas escolas.

Tais ações buscam medidas que ultrapassam as fronteiras das escolas e universidades, reproduzindo uma lógica de gênero como conceito destrutor de forma totalitária das famílias brasileiras, sendo as mulheres e os papéis atribuídos a elas objeto fundamental para reafirmação de tais modelos de família e consequentemente de sociedade. Trata-se de elemento discursivo pertencente a uma articulação e formação discursiva maior, a qual fere a

17 "prega o menor estado possível e afirma que qualquer situação que nasça de mecanismos de mercado é justa por definição, por mais desigual que pareça" (ROTHBARD, 1970 apud MIGUEl, 2016: 592).

18A doutrina do falecido presidente venezuelano Hugo Chávez.

19 “[...] aqueles que emergem a partir do medo social com relação às mudanças, especialmente as percebidas como repentinas e, talvez por isso mesmo, ameaçadoras” (MISKOLCI, 2007, p. 103).

${ }_{20}$ Partido Social Liberal. 
laicidade e a autonomia das instituições educacionais conduzidos por suas fantasias sociais sobre gênero e sexualidade.

Laclau e Mouffe, (2015, p. 213), consideram uma prática articulatória como o campo geral da emergência da hegemonia, na qual os elementos não se cristalizam em momentos. Assim, a "ideologia de gênero" não se trata de um discurso fechado - com atores e enunciados fixos - , pelo contrário, se dá em forma de elementos por meio de articulações e antagonismos com outros elementos discursivos provenientes de uma mesma lógica social, que estão em constantes disputas com outras lógicas, sujeitos e atores/atrizes no campo geral da discursividade.

A perspectiva antigênero, conforme a TD permite analisar, é um elemento discursivo que se configura através de lógica fantasmática atravessada por fundamentos religiosos, éticos, morais e culturais que, segundo os interesses dos sujeitos e grupos de tais articulações, devem ser considerados universais, imutáveis e indiscutíveis por serem "saudáveis" e por tornarem possíveis as manutenções dos "estilos de vida" defendidos por determinados grupos. Dessa forma, ressalta-se que as TG, os movimentos feministas e LGBTQI+, professores/as e pesquisadores/as das ciências humanas representam o antagonismo a esta articulação, sendo, portanto, acusados de apoiarem e difundirem o suposto "marxismo cultural".

\section{As instituições de ensino enquanto espaços discursivos democráticos e de diversidade: gênero e sexualidade para o reconhecimento dos sujeitos invisibilizados}

Embora existam avanços significativos nos segmentos políticos/sociais, as questões de gênero e de orientação sexual ainda se apresentam como conteúdos ameaçados pelos discursos morais e políticos de grupos reacionários e ultraconservadores da sociedade. As instituições de ensino, neste cenário, permanecem limitadas aos problemas causados pela normatização do gênero e da heterossexualidade compulsória, ainda que continuem sendo privilegiados espaços de formações discursivas para se pensar a diversidade sexual e de gênero de forma política/social.

A relevância das instituições de ensino para responder aos diversos "embates hegemônicos" que circundam o campo das políticas de gênero e de população LGBTQI+ é perceptível dentro das narrativas que difundem a "ideologia de gênero". Este elemento discursivo antigênero configura-se como uma tentativa de instrumentalizar tais organizações e o próprio processo educativo enquanto ambiente homogêneo em relação às lógicas sobre sexo, gênero e família, baseando-se em princípios religiosos e fundamentalistas. Estes, 
segundo Miguel (2016), ganharam força na década de 90, sobretudo, com o investimento das igrejas neopentecostais nos processos eleitorais de seus pastores. Tais fundamentalismos e o modo que exercem suas forças discursivas sobre o social podem ser facilmente localizados a partir de suas relações interdiscursivas com os próprios discursos agnotológicos, fato que revela intrínseca relação e diálogo entre os campos discursivos políticos e religiosos.

\footnotetext{
O fundamentalismo se define pela percepção de que há uma verdade revelada que anula qualquer possibilidade de debate. Ativos na oposição ao direito ao aborto, as compreensões inclusivas da entidade familiar e a políticas de combate à homofobia, entre outros temas, os parlamentares fundamentalistas se aliam a diferentes forças conservadoras no Congresso, como os latifundiários e os defensores dos armamentos, numa ação conjunta que fortalece a todos. Fora do Congresso, pastores com forte atuação política e forte presença nas redes sociais, como Silas Malafaia (da Assembleia de Deus Vitória em Cristo), dão voz à sua pauta. (MIGUEL, 2016, p. 593).
}

Aliados a setores mais conservadores da Igreja Católica e aos interesses econômicos do ultraliberalismo - tendo como uma de suas figuras representativas o autointitulado filósofo, também adepto ao anticomunismo e propagador do "marxismo cultural" Olavo de Carvalho - tais grupos ameaçam a educação brasileira e a fazem refém de políticas que servem aos seus interesses, principalmente no que diz respeito às medidas impositivas no âmbito moral.

O discurso ultraliberalista original, fiel à ideia de que cada um é proprietário de si mesmo, tenderia a assumir agenda "progressista" em relação a temas como liberação das drogas, direito ao aborto, arranjos familiares heterodoxos e/ou direitos dos homossexuais neste último caso, com alguma vacilação, dada a homofobia obsessiva de uma de suas autoras icônicas, a romancista de ficção científica Ayn Rand21. No Brasil, o fortalecimento público deste discurso abertamente conservador permitiu que ganhasse visibilidade e expressão parlamentar o movimento chamado "Escola Sem Partido". Este acusa as escolas e Universidades de promoverem a doutrinação ideológica de estudantes e propõe medidas para impedir professoras e professores de expressarem opiniões, consideradas pelo movimento como impróprias em sala de aula (MIGUEL,2016, p. 594).

Sendo assim, estes discursos passaram a desconsiderar os estudos progressistas na área das ciências humanas, os quais, majoritariamente, apontam a omissão dos debates sobre a

21 A autora apresentou opiniões controvérsias sobre homossexualidade e papeis de gênero. Para ela, a homossexualidade era negativa, imoral e repugnante. Além disso, em seu ensaio chamado A era da inveja (1971), ela faz uma critica ao movimento de libertação das mulheres, caracterizando-o de forma pejorativa como "frente comum com lésbicas e prostitutas". Entre as diversas polêmicas envolvendo as temáticas de gênero e sexualidade, a autora defendia "o direito" de discriminar uma pessoa homossexual em setores privados, a partir de noções sobre "direitos de propriedade". 
diversidade sexual e de gênero como algo nocivo e causa de malefícios às relações existentes nas instituições de ensino, sobretudo nas escolas. Além disso, são desconsideradas as lutas e avanços no território latino-americano em matérias de direitos sexuais e reprodutivos. Para Scala22 (2011), tais direitos são meros resultados da manipulação da linguagem.

\begin{abstract}
A luta contra a "ideologia de gênero" é uma forma de resistência contra os recentes avanços que vêm se dando na América Latina em matéria de direitos sexuais e reprodutivos. Jorge Scala (2011, p. 30) considera que tais direitos não são mais do que o resultado da manipulação da linguagem, em que os "ideólogos de gênero" convencem a seus interlocutores afirmando tratar-se de direitos humanos e assim os "submetem" sem resistência já que "tudo aquilo que se apresenta ao povo como fruto de um consenso democrático imediatamente é considerado como algo bom mesmo quando é um ato criminoso", posto que ninguém poderia opor-se à defesa dos direitos humanos (MISKOLCI e CAMPANA, 2017, p. 728).
\end{abstract}

A discussão direcionada ao ambiente escolar e às universidades ocorre como um combate aos conteúdos de gênero e sexualidade que estão sendo associados a estereótipos de governos de esquerda por forças religiosas, partidos políticos com interesses incomuns e setores reacionários da sociedade. Tal configuração, além de se distanciar do que seria um debate amplo e democrático, chega às instituições de ensino de forma verticalizada e violenta, ferindo a autonomia dos/das profissionais de educação, naturalizando violências de gênero e orientação sexual e retirando, sobretudo, o direito ao saber, à criticidade e ao questionamento, necessário para as relações no processo de ensino e aprendizagem. Como aponta Louro (2000a, p.60) ao se referir a uma "escolarização do corpo", a escola seria uma instituição que, aplicando a "pedagogia da sexualidade", conseguiria disciplinar os corpos de maneira sutil em prol da dessexualização do espaço escolar. (LOURO, 2000b, p. 13)

a preocupação com o corpo sempre foi central no engendramento dos processos, das estratégias e das práticas pedagógicas. $\mathrm{O}$ disciplinamento dos corpos acompanhou, historicamente, o disciplinamento das mentes. Todos os processos de escolarização sempre estiveram - e ainda estão - preocupados em vigiar, controlar, modelar, corrigir, construir os corpos de meninos e meninas, de jovens homens e mulheres. (LOURO, 2000a, p. 60)

Para Cáudia Viana e Sandra Ridenti (1998), o ambiente escolar pode reforçar as desigualdades de gênero quando não permite posicionamentos críticos diante dos preconceitos. Constatam-se, então, os perigos e limitações que os significados de "ideologia

22Argentino que defende a existência de uma "ideologia de gênero" como uma pseudoantropologia feminista com pretensões à "reengenharia social". 
de gênero" implicam quando inseridos nos ambientes educacionais/políticos, impossibilitando os debates e consequentemente as transformações, discussões e compreensões que emergem a partir deles.

Diante desse cenário agnotológico, a profissionalização docente tem sido o alvo de ataque desses discursos políticos. Paralelamente a essa realidade, cresce o número de estudos norteadores da escola como espaço reprodutor de machismo e LGBTfobia.

Muitos são os problemas causados pela omissão da escola em relação à LGBTfobia e ao machismo - violências relacionadas aos papéis de gênero e orientações sexuais — que continuamente são resumidos ao termo bullying. É vital pontuar que estes tipos de violência se dão através de uma articulação hegemônica maior que envolve gêneros discursivos do universo escolar, como os documentos curriculares oficiais, as atividades escolares, o fardamento, as atividades físicas e os livros didáticos. Tais articulações colocam estabelecem a heterossexualidade como padrão comportamental, sendo possível até mesmo que pessoas heterossexuais sofram com o processo de normatização dos corpos. Por exemplo, quando um garoto heterossexual representa alguma espécie de feminilidade, logo passa a ser chamado de "bichinha", "mulherzinha", etc. Estas formas de violência não fazem parte das diretrizes de educação previstas na legislação brasileira que, apesar de ignoradas, ainda garantem o respeito à diversidade e o espaço escolar como múltiplo e heterogêneo.

É necessário que haja professores/as aptos/as para lidar com tais questões em sala de aula e que seja garantido o direito a aprender, discutir e debater gênero e sexualidade no ambiente escolar para além da concepção biologizante - principal responsável pela redução dos problemas sociais a "fenômenos naturais" por muito tempo. Tais possibilidades de desmistificação e desconstrução do social não fazem dos espaços educacionais instrumentos de qualquer partido, pelo contrário, os tornam espaços de exercício aos direitos humanos, também deslegitimados pelos setores reacionários da sociedade. Reitera-se a educação enquanto processo de acolhimento e não de exclusão, de diálogo entre mundos e concepções e não apenas espaço discursivo hegemônico e fixador de sentidos padronizados e robotizados sobre os sujeitos, servindo a interesses de grupos específicos.

Aqui, quando se fala do social como ontologicamente político, refere-se à "negatividade do social", ao seu caráter contingente que revela as impossibilidades dos discursos científicos positivistas e totalizantes. O espaço discursivo/educacional, nesse sentido, não se dá fora do que é político, pois as formações discursivas, dentro da perspectiva aqui trabalhada, se constituem em um campo geral da discursividade, no qual a realidade não pode ser alcançada, nem sequer analisada no seu sentido total e fechado. É no sentido aberto 
do social que também é mencionada a impossibilidade de fixação dos sentidos, pois a própria ontologia, como superfície do discurso científico, permite o apontamento das precariedades, contingencialidades e impossibilidades de fechamento de qualquer identidade e/ou formação hegemônica. Ademais, é partir do antagonismo denunciante da incompletude de qualquer formação discursiva que se reflete, analisa e observa - através das lógicas políticas formas de resistência aos modelos sociais hegemônicas. Se existe, portanto, a possibilidade de antagonismo, existe possibilidades de resistência.

É perceptível que as escolas e as universidades — dentro desse cenário agnotológico, anticiência, antigênero e antidemocrático - são tidas como lugares em que a moralidade de grupos hegemônicos deve ser reproduzida e aceita como verdade absoluta e estrutural no tangente à educação formal. Nesse sentido, as mulheres em suas pluralidades, as pessoas LGBTQI+ e os comportamentos dissidentes à heteronormatividade passam a ser compreendidos como símbolos e representações de afrontas diretas às concepções antipedagógicas sobre o sexo e gênero, sendo também objetos de debates nos meios religiosos e considerados como causadores polêmicas e mutações sobre a própria concepção de família na contemporaneidade.23.

A “ideologia de gênero" ou crença nas desigualdades de gênero ao mesmo tempo em que se estabelece de forma nociva, por seu caráter antigênero, evidencia que o meio político institucional reconhece a potência das escolas e universidades públicas enquanto alicerces culturais dos sujeitos que passam por elas, e, portanto, disputam-se esses espaços em busca de fixação e hegemonia de suas pedagogias sobre gênero e sexualidade.

\section{Conclusão}

Dado o exposto, compreende-se que a "ideologia de gênero" se consiste como elemento discursivo que tem se apresentado à sociedade de forma difusa, baseando-se tipicamente em uma suas crenças e fantasias biologizantes. Tal elemento discursivo faz parte de uma articulação transnacional, a qual tem por objetivo impedir o ensino de gênero e orientação sexual nas instituições educacionais. Essa tentativa faz parte de um processo histórico/contingente que parte de determinados grupos ligados ao catolicismo, tendo hoje o protestantismo com forte participação, e grupos políticos de direita.

A ideia de "ideologia de gênero" emerge de um momento político, no qual há notório avanço de grupos conservadores/totalitários da sociedade, não só no Brasil, que compreendem

${ }_{23}$ Um exemplo disso se dá através do número de Igrejas Inclusivas que crescem no Brasil. 
as instituições de ensino como campos discursivos táticos para a implementação de lógicas políticas e sexuais correspondentes aos seus valores morais. Para isso, houve a criação de certo pânico moral em torno da categoria gênero através da utilização desse instrumento retórico.

Contrapondo-se a este recurso discursivo, reafirmam-se aqui as contribuições de Kroska (2007) que, por meio de abordagem sociológica, ajuda a desfazer as confusões e sentidos difusos acerca da "ideologia de gênero", trazendo à tona o sentido de valores reforçadores das desigualdades entre homens e mulheres associados às concepções religiosas sobre família e ao combate dos avanços em matéria de direitos sexuais e reprodutivos. Como bem elucidou Bernini (2018, p. 543), além de tomar consciência sobre a radicalidade dos conflitos que envolvem a "ideologia de gênero", é necessário se posicionar a respeito.

Por fim, afirma-se que a "ideologia de gênero", difundida pelos grupos antigênero, não se trata de um sinônimo das TD, mas de uma crença antigênero que parte da visão unilateral e biologizante acerca das discussões de gênero e sexualidade, visando manter a perpetuação das hierarquias e desigualdades de gênero existentes na sociedade e tratando as instituições de ensino como esteira para a reprodução e implantação de lógicas, valores e moralidades conservadoras e reacionárias.

\section{Referências}

ÁVILA, Maria Betânia. Direitos sexuais e reprodutivos: desafios para as políticas de saúde. Caderno de Saúde pública. Rio de Janeiro, v.19, n.2, ago./set. 2003. Disponível em:https://www.scielo.br/scielo.php?script=sci_arttext\&pid=S0102311X2003000800027. Acesso em: 19. jun. 2020.

BERNINI, Lorenzo. A “teoria do gender” na Itália: um posicionamento circunstanciado sobre um significante flutuante. Psicologia Política, São Paulo, v. 18, n. 43, set./dez. 2018. Disponível em: 〈http://pepsic.bvsalud.org/pdf/rpp/v18n43/v18n43a07.pdf>. Acesso em: 22. jun. 2020.

BUTLER, Judith. Precisamos parar o ataque à "Ideologia de Gênero". Sexuality Policy Watch, 2019. Disponível em: https://sxpolitics.org/ptbr/judith-butler-precisamos-parar-oataque-a-ideologia-de-genero/9094. Acesso em: 22. Jun. 2020. 
CORREA, Sônia. Gender Ideology: tracking its origins and meanings in current gender politics. Engenderings, London School of Economics, December, 2017. Disponível em: <https://blogs.lse.ac.uk/gender/2017/12/11/gender-ideology-tracking-its-origins-andmeanings-in-current-gender-politics/\#_ftn2>. Acesso em: 10. jan. 2020.

CORREA, Sonia; KALIL, Isabela. Políticas antigénero en américa latina: brasil - ¿la catástrofe perfecta? Observatorio de Sexualidad y Política (SPW), 2020. Disponível em: https://sxpolitics.org/GPAL/uploads/Ebook-Brasil\%2020200204.pdf. Acesso em: 22 jun. 2020.

GLYNOS, Jason; HOWARTH, David. Explicação críticas em ciências sociais: a abordagem das lógicas. In: LOPES, Alice Cassimiro; OLIVEIRA, Ana Luiza Ramos Martins de; OLIVEIRA, Gustavo Gilson Souza de. A teoria do discurso na pesquisa em educação. Recife: Editora UFPE, 2018. p. 53-102.

KROSKA, Annie. Gender ideology and gender role ideology. In: RITZER, George. (Ed.). The Blackwell Encyclopedia of Sociology. Oxford: Blackwell Publishing. p.1867-1868, 2007.

Laclau, Ernesto e Mouffe Chantal. Hegemonia e Estratégia Socialista: por uma política democrática radical. 1. Ed. São Paulo: Editora Intermeios, 2015. 286 p.

LEITE, José Correa. Controvérsias científicas ou negação da ciência? A agnotologia e a ciência do clima. Scientiae Studia. São Paulo, v.12, n.1, jan./mar. 2014. Disponível em: https://www.scielo.br/scielo.php?pid=S167831662014000100009\&script=sci_arttext\#: :text= O\%20prop\%C3\%B3sito\%20da\%20agnotologia\%20seria,pontos\%20da\%20hist\%C3\%B3ria\% 22\%20(Proctor\%20\%26. Acesso em: 22. jun. 2020.

LOPES, Alice Casimiro. Articulações de demandas educativas (im)possibilitadas pelo antagonismo ao “marxismo cultural”. Revista Arquivos Analíticos de Políticas Educativas, Arizona State University, v. 27, n.109, set. 2019. Disponível em: https://epaa.asu.edu/ojs/article/view/4881. Acesso em: 22. jun. 2020. 
LOURO, Lopes Guacira. Corpo Escola e Identidade. Educação e Realidade. Rio Grande do Sul, v.25, n.2, jul./dez. 2000b. Disponível em

<https://seer.ufrgs.br/educacaoerealidade/article/view/46833>. Acesso em: 22. jun. 2020.

LOURO, Lopes Guacira. O corpo educado: pedagogias da sexualidade. 2. ed. Belo Horizonte: Autência Editora, 2000a. 127. p

MIGUEL, Luis Felipe. Da "doutrinação marxista” à "ideologia de gênero" - Escola Sem Partido e as leis da mordaça no parlamento brasileiro. Direito e Práxis Revista. Rio de Janeiro, v. 7, n. 15, ago. 2016. Disponível em:

https://www.epublicacoes.uerj.br/index.php/revistaceaju/article/view/25163/18213.Acesso em: 12 mai. 2020.

MISKOLCI, Richard. Pânicos morais e controle social - reflexões sobre o casamento gay*. Cadernos Pagu. v.1 n. 28, jan./mar. 2007. Disponível em:

https://www.scielo.br/pdf/cpa/n28/06.pdf. Acesso em: 22. jun. 2020.

OLIVEIRA, Ana Luiza Ramos Martins de; OLIVEIRA, Gustavo Gilson Souza de. Novas tentativas de controle moral da educação: conflitos sobre gênero e sexualidade no currículo e na formação docente. Educação Tunisinos, v. 22, n.1, jan./mar.,2010. Disponível em: http://revistas.unisinos.br/index.php/educacao/article/view/edu.2018.221.02. Acesso em: 22. jun. 2020.

OLIVEIRA, Gustavo Gilson de. Provocações para aguçar a imaginação/invenção analítica: aproximações entre a teoria política dos discurso e análise do discurso em educação. In: LOPES, Alice Cassimiro; OLIVEIRA, Ana Luiza Ramos Martins de; OLIVEIRA, Gustavo Gilson Souza de. A teoria do discurso na pesquisa em educação. Recife: Editora UFPE, 2018. p. 169-216.

PATERNOTTE, David e KUHAR, Roman. "Ideologia de gênero" em movimento. Psicologia Política, São Paulo, v. 18, n. 43, set./dez. 2018. Disponível em: http://pepsic.bvsalud.org/scielo.php?script=sci_arttext\&pid=S1519-549X2018000300005. Acesso em: 19. jun. 2020. 
PRADO, Marco e CORREA, Sonia. Retratos transnacionais e nacionais das cruzadas antigênero. Psicologia Política, São Paulo, v. 18, n. 43, set./dez. 2018. Disponível em: http://pepsic.bvsalud.org/pdf/rpp/v18n43/v18n43a03.pdf. Acesso em: 19. mar. 2020.

PROCTOR, Robert N. Agnotology: a missing term to describe the cultural production of ignorance (and its study). In: ROBERT N. Proctor e LONDA Schiebinger. Agnotology: the making and unmaking of ignorance. Stanford: Stanford University Press, 2008. p. 02-36.

RAMÍREZ, Arguedas Gabriela. “Ideología de género”, lo "post-secular”, el fundamentalismo neopentecostal y el neointegrismo católico: la vocación antidemocrática. Observatorio de Sexualidad y Política (SPW), 2020. Disponível em:

https://sxpolitics.org/GPAL/uploads/Ebook-Apartado\%2020200203.pdf. Acesso em: 07 mai. 2020.

REIS, Toni; EGGERT Edla. Ideologia de gênero: uma falácia construída sobre os planos de educação brasileiros. Educ. Soc., v. 38, n. 138, p.9-26, jan.-mar, 2017.

MISKOLCI Richard e CAMPANA Maximiliano. "Ideologia de gênero”: notas para a genealogia de um pânico moral contemporâneo. Revista Sociedade e Estado, v.32, n.3, set./dez. 2017.

SCALA, J. Ideologia de Gênero: o neototalitarismo e a morte da família. São Paulo: Katechesis, 2011. 200 p.

SILVA, Silas Veloso de Paula. Diversidade de gênero e "Ideologia de gênero" na educação: estudo de caso em uma escola do Recife. 2019. 71.f. Monografia (Trabalho de Conclusão de Curso em Ciências Sociais), Universidade Federal de Pernambuco, Recife, 2019.

SILVA, Silas Veloso de Paula; NARA, Isabela Costa Alves; BARRETO, Fernanda Gueiros Vidal. "Ideologia de gênero" e escola sem partido: desafios do ensino da sociologia na política brasileira a partir dos embates hegemônicos em torno da educação. Revista Diversidade e Educação. V. 8, n.1, (no prelo). 
VIANNA, Cláudia Pereira.; RIDENTI, Sandra. Relações de gênero e escola: das diferenças ao preconceito. In: AQUINO, Julio G. (Org.). Diferenças e preconceito na escola: alternativas teóricas e práticas. São Paulo: Summus, 1998, p. 93-105.

Recebido em maio de 2020.

Aprovado em junho de 2020. 